without success. Massage was now resorted to, and efforts made to reduce the invagination by manipulation of the abdomen, but without any effect. Finally, inflation of air was tried, but this attempt was also unsuccessful. As it seemed improbable that reduction would be effected without operation, laparotomy was determined upon. At 8 P.M., the child having been placed under the influence of chloro. form, an incision, about three inches in length, was made in the linea alba, and the peritoneal cavity opened. There was found to be an invagination of the small intestines into the large at the ileo-crcal valve, the invaginated portion of bowel extending as low as the anus. It was reduced withont difficulty. After its reduction the coats of the descending colon were noticed to be much thickened and oedematous. The reduction was eifected without the escape of any of the intestines from the abdominal cavity. The wound was closed and dressed.

The next morning (March 3rd) the child was found to have passed a good night and to have slept soundly. It looked quite well, and seemed free from pain. There had been no vomiting, and it had taken food freely. Two motions had been passed during the night of fairly natural consistence. Previously to this, however, and shortly after the operation, it had passed a little blood and mucus. The temperature was $99^{\circ}$; the pulse 140 ; respiration 40 .

Early on the following morning (the 4th), until which time the child had been apparently going on well, it awoke with much crying, and seemed in great pain. The bowel was found to be protruding from the anus. Mr. Pick reopened the wound and reduced the intussusception a second time. The wound was found to be in a satisfactory state, and there was no evidence of peritonitis. There was much collapse at the time of the operation and incessant vomiting afterwards. A little slime was passed during the day, but no faces or urine. The child died at 11.55 P.M.

Necropsy.-The body was well nourished. Rigor mortis was present. There was an incision between the umbilicus and pubes. The intestines were distended; the omentum covered a little blood clot opposite the laparotomy wound. There was no peritonitis; no intussusception. The cæcum was distended; the vermiform appendix free. The small bowel was normal. The large bowel showed patches of congestion in the ascending colon. No evidence of constriction on the mesentery. The stomach contained dark fluid. The liver was pale and fatty, but firm. Gall-bladder full bile-ducts pervious. Spleen, pancreas, testes, bladder, and kidneys normal. There was a large mesenteric gland near the cæcum. The pleuræ were normal. The lungs showed numerous dark-purple broncho-pneumonic patches, least marked in the right lung. The bronchi and trachea contained similar material to that found in the stomach. There was no tubercle. The larynx, thyroid, bronchial glands, heart, and pericardium were normal.

Pemarks by Mr. PICK.-In this case it was not until a thorough and patient trial of other means of reduction had been resorted to and failed that laparotomy was performed ; and the operation on the following day seemed likely to prove successful. The child seemed quite well, and free from pain and sickness; it took its food well, and the bowels acted twice naturally. Of course, in considering the question of the recurrence of the intussusception, the idea suggests itself to one's mind that the invagination was not completely reduced at the first opera. tion. But the condition of the child on the day after operation seems to preclude this idea; the absolute cessation of all the previous symptoms of obstruction and the healthy action of the bowels seem to prove that the intussusception was really reduced. Even after the reopening of the wound and the second reduction there seems no reason to doubt, fron the post-mortem evidence, that the child might have recovered had it not been for the unfortunate accident of some of the vomited food finding its way into the air passages, which was the immediate cause of death.

VICTORIA HOSPITAL FOR CHILDREN.

A CASE OF INTUSSUSCEPTION; REDUCTION DY INFLATION ; CONTINUANCE OF SYMPTOMS ; SUBSEQUENT LAPAROTOMY ; DEATH.

(Under the care of Mr. PICK.)

To a considerable extent the editorial remarks prefixed to the case of intussusception treated by laporotomy (and again by laparotomy when the disease returned), recorded above, which was also under the care of Mr. Pick, apply to this case. In a large number of instances the return of symptoms or their continuance after the use of inflation or injections into the bowel is due to incomplete reduction of the intussusception. How frequently the abdominal tumour seems to disappear under treatment, only to show itself a few hours later. We seldom meet with the condition of bowel after intussusception which was found at the operation on this patient, and it is of considerable importance a record of such instances should be made. More can be learnt from the account of such a case than by the perusal of many uncomplicated cases, where inflation or injection treatment has been used with success.

A. R. D-, aged six months, was admitted into the Victoria Hospital on Oct. 26th, 1887. The child was reported to have been always strong and healthy. It had been fed at the breast and on nursery biscuits, and had had no illness of any kind. Its bowels had always acted regularly, and it had never been troubled with sickness, diarrhoea, or constipation. The family history was good; no bistory of syphilis or of phthisis. The child had been fretful for three weeks past, but seemed otherwise well until the $23 \mathrm{rd}$, when it vomited after taking the breast and then refused it. The mother took it to a medical man, who said it was suffering from flatus, and prescribed for it. On the following morning the child was worse, and evidently in great pain; the mother accordingly gave it a teaspoonful of castor oil, which produced a bloody motion, containing slime. The sickness continued and the pain seemed to increase, the child writhing and kicking its legs about. It seemed now willing to take the breast, but the mother was advised not to put the child to it, and accordingly abstained from giving it any food until the next morning. On the 25 th (the day before admission) the child was constantly sick, and evidently in great pain; there was constant tenesmus and passage of blood and mucus per anum. Very little urine had been passed since the illness began. On admission the child was found to be well nourished and healthy-looking. Temperature $99^{\circ}$; pulse 100 . It lay on its back perfectly quiet, and apparently free from pain, except that every now and then it cried in a moaning fashion and writhed, drawing its thighs up on to the abdomen as if in a paroxysm of pain. The pain only seemed to last about half a minute. The tongue was moist. There was no distension or dulness of the abdomen, and its walls were lax and could be easily palpated. On the left side was a distinct sausage-shaped tumour, feeling about three to four inches long, movable, and running in a direction obliquely to the outer side of the umbilicus. It did not appear to be tender. On examina. tion by the rectum nothing abnormal was to be felt. Shortly after admission the child passed a small quantity of blood, merely sufficient to stain the napkin. At 6 P.M. it was sick after taking milk. At 10 P.M. it was reported to have besn sick twice. At 1 A.M. on the morning of the 27 th the child was placed under the influence of chloroform, and, having been inverted, air was forced up the bowel by means of a pair of bellows. As the air was introduced it could be felt distending the colon by the hand placed upon the abdomen. Suddenly the sausage-shaped tumour seemed to melt away from under the fingers and the air rapidly diffused itself over the whole of the abdomen. The child was now sent back to bed, and an enema of one drachm of starch with two minims of tincture of opium administered. This was partly returned, streaked with blood. The child slept for two hours, and was then sick after taking a little milk. There was no action of the bowels. At 9 A.M. the child looked worn and anxious. Pulse 130. Abdomen hard and tense on palpation; no swelling to be felt. No action of the bowels. A poultice was applied to the abdomen, and the child was ordered to have nothing by the mouth but half a teaspoonful of raw meat juice, with two drops of brandy, every two hours. An oil enema was given, but it was returned with slimy mucus and blood. At 4 P.M. the pulse was 140 , temperature subnormal. The child seemed to be in more pain; it had not been sick since it began the meat juice. Bowels not acted.

Oct. 28th.-At 11 A.M. the child was manifestly worse there was a drawn and anxious expression of countenance, and it was constantly moaning and tossing about, as if in pain. The bowels had not been opened, but there had been passage of some blood and mucus. The face was slightly flushed, pulse quick, tongue moist and clean. The abdomen was still hard and tender, and slightly distended, mani- 
pulation evidently causing pain. At.2 P.M. the child was evidently worse, and appeared to be sinking. As the symptoms seemed to point to the fact that the intussusception had not been completely reduced, it was determined to perform laparotomy. This was accordingly done under chloroform, with strict antiseptic precautions. After the abdomen had been opened in the linea alba the small intestines were found to be distended with air and congested, but there was no marked sign of peritonitis. On tracing this part of the bowel a piece was found about six inches long, which was completely contracted and empty, and looked as if it were paralysed. There was a slight constriction at each end of the contracted portion, and the bowel below was empty and collapsed; but there were no signs of previous strangulation, neither congestion, change of colour, nor roughness of surface. The large intestine seemed healthy, and no intussusception was found. Nothing further being discoverable, the peritoneal cavity was washed out with a solution of boracic acid, closed, and dressed. The operation lasted twenty-five minutes.

The result of the operation was therefore unsatisfactory ; for, assuming that the contracted portion of small intestine represented the seat of intussusception and that the entire colon was unaffected, it remains unexplained why the inflation should have been attended with such a marked and sudden disappearance of the tumour, and why, with such a slight amount of constriction and inflammation, the symptoms should have continued unchanged. The child bore, the operation well, but suddenly became collapsed, and died about three hours afterwards.

Remarks by Mr. PrCK. - This case is a good example of the success which attends inflation with inversion, as far as the reduction of the intussusception is concerned, and it seems difficult to understand why the child was not permanently relieved. It wonld seem probable that the intussusception was one of the small intestine, and that the portion of the bowel which at the subsequent laparotomy was found to be contracted and empty was the part which had been invaginated, and that it had been so long confined that after its release had taken place it was unable to recover itself, and therefore the symptoms continued unchanged. The question which presses itself npon one's mind is whether the bowel might have eventually recovered itself, and whether it would have been wiser to have left the infant alone, and not have resorted to operative interference. But at the time this was undertaken the child was manifestly worse and appeared to be sinking, and had apparently derived no benefit from the supposed reduction of the intussusception. It was therefore believed that the invagination had not been completely reduced, or that there was a second intussusception or some other cause of obstruction, and therefore the operation was undertaken. It is to be regretted that no post-mortem examination could be obtained.

\section{attedital Soriefies.}

\section{ROYAL MEDICAL \& CHIRURGICAL SOCIETY.}

Acute Inflammation of the Mucous Membrane of the Ileum from Climatic Causes. - Pancreatic Cyst treated by Laparotomy.-Causation of Pes Cavus.

THE last ordinary meeting of this Society for the present session was held on June 9th, the President, Mr. TIMothy HOLMES, being in the chair.

Dr. GEorge ThIN and Dr. Frank J. WeThered commuxicated a paper on the Symptoms and Pathology of a case of Acute Inflammation of the Mucous Membrane of the Ileum from climatic causes. The patient whose case was described in the paper was a man with strong constitution, and in the enjoyment of excellent bealth. Whilst travelling in the north of China in the autumn, he became, after a chill, subject to a moderate but obstinate diarrhoea. After several months, the tendency to diarrhoca increasing, he became subject to febrile attacks, and after three months of the combined moderate fever and diarrhœa he had lost forty ponnds in weight, and was sent to Europe. The condition became aggravated on his way home, his journey being broken for six weeks on account of a very acute illness, of which the leading features were diarrluen, retching, nausea, and fever, his condition for three weeks of that time being critical. After a comparatively rapid convalescence, during which time he regained his normal weight, he enjoyed three months of good health and appeared perfectly well. A chill brought on another acute attack, the general sym. ptoms of which were fever, nausea, abdominal uneasiness, thirst, entire loss of appetite, and complete incapacity to digest food. During the whole of his illness there was diarrhœa, the intestinal discharge consisting of a darkcoloured fluid with an apparent absence of any frecal ele. ment. Death took place at the end of five weeks from the seizure. A necropsy was made by Dr. Sidney Martin. The mucous membrane of the ileum presented a worm eaten appearance along its whole course. There were superficial ulcerations not extending deeper than the mucous mernbrane, and in some places there were discrete erosions of the size of a split pea. The ulceration increased as it descended the ileum, and the mucous membrane seemed somewhat thickened. At the entrance of the vermiform appendix into the cæcum the mucous membrane was thickened and slightly eroded. In the whole of the large intestine there were only about ten superficial ulcers, al! of which were close to the cæcum, five being grouped together, this gut being otherwise healthy. The stomach and jejunum were unaffected, and there was nothing remarkable in the liver or spleen. Dr. Wethered prepared specimens of the viscera, and on microscopical examination the anthors of the paper found the following morbid appearances in the ileum, No traces of the villi were observed. Lieberkuihn's crypts in the least diseased parts were not affected at their deep ends, but were indistinct towards the free edge of the mucous membrane, and lost in a finely granular substance which corered the whole of that part of the gut. At some parts, whilst the epithelium of the crypts could be recognised as much altered at their deep ends, atrophy and destruction had occurred at a short distance from their base, a mucoidlooking material distending the lower part of the crypt. In some parts the whole crypt was disintegrated, its position being indicated by the broken-down remnants of the epithelial cells. At the seat of the erosions the epithelium had entirely disappeared, the free surface being covered with a layer of granular material similar to that which covered the less affected parts of the gut, and below this substance there was a thick mass of small cell infiltration in the whole of the submucous layer. The muscular and subperitoneal coats were comparatively unaffected. The mucous membrane of the large intestine as a whole, and all the upper parts of the intestinal canal, were normal. The authors had not been able to find any record of a case of acute inflammation of the mucous membrane of the intestine limited to the ileum and involving the whole of its surface. Clinically it was shown in the paper in what respects the symptoms differed from typhoid fever and dysentery, the two diseases in regard to which questions of differential diagnosis could arise. Special attention was called to the apparent absence of fæcal elements in the intestinal dis. charge, and of the suspension of the digestive functions, notwithstanding that the stomach, duodenum, jejunum, and liver were comparatively healthy. Milk and raw egg, when not rejected by vomiting, passed in the motion entirely unaltered, and it was suggested that this suspension might at least partly have been due to a reflex effect from the inflamed mucous membrane of the ileum.Dr. SCRIVEN said that during his thirty years' practice in India be could call to mind a few such cases, attended by diarrhcea and fever. He asked if the authors had any record as to the food and kind of water the patient had consumed while in China. He thought the affection was more attributable to alimentation than to climate.Dr. JoHNson said that the patient had been well known to him during his career in the East. $\mathrm{He}$ was very robust for his age, and he was struck, when he met him later in London, to see how greatly his physique had changed. He had attended him abroad for two attacks of malarial fever, for the latter of which he had been invalided lome. While in China he had lived well, though he bad not been guilty of excess. Though he was not actually suftering from sprue, yet his mucons membrane was undergoing changes which were leading up to that disease. Long residence in a malarious country brought about an insidious change in the intestinal mucous membrane which might develop at any time into an acute disease. It was rare to see the processes of nutrition suspended in even acute attacks of malarial disease - Dr. SouIne said that the 